\title{
JUSTIÇA FISCAL COMO MECANISMO DE PROMOÇÃO DO DESENVOLVIMENTO NACIONAL
}

\section{TAX JUSTICE AS PROMOTION MECHANISM OF NATIONAL DEVELOPMENT}

\author{
${ }^{1}$ Bruno Bastos De Oliveira \\ ${ }^{2}$ Edjane Barbosa De Freitas Araújo
}

\section{RESUMO}

A necessidade de concretização do projeto de desenvolvimento existente em nossa Carta Magna, não podendo ser entendido apenas no âmbito político, econômico ou social, mas sim no conjunto de todos eles, é premente. Analisando tal situação à luz do Direito Tributário, sua concretização instrumentaliza a efetivação das igualdades e liberdades fundamentais dos contribuintes, por meio do Estado, o qual possui o poder regulador de todo o ordenamento jurídico tributário. Assim, atualmente, o Estado tem sido responsável por delinear e estabelecer limites a um propulsor e desenfreado pseudodesenvolvimento, ao invés de traçar caminhos e métodos efetivos para que o contribuinte possa exercer o direito-dever de pagar tributos de forma justa e humanizada, a partir da materialização da capacidade contributiva. A reforma tributária é umas das principais vias instrumentais de promoção da justiça fiscal em prol do desenvolvimento nacional. Importante assim analisar a justiça fiscal tributária como forma de consolidar um dos objetivos fundamentais da Constituição, que é o desenvolvimento nacional, e em contrapartida o fundamental papel do Estado como detentor de toda competência impositiva no âmbito tributário.

Palavras-chave: Justiça fiscal, Tributário, Desenvolvimento

\begin{abstract}
The need for implementation of existing development project in our Constitution and can not be understood only in the political, economic or social, but in all of them all, is pressing. Analyzing this situation under Tax Law, its implementation exploits the realization of equality and fundamental freedoms of taxpayers, through the state, which has the regulatory power of the entire tax law. Thus, currently, the State has been responsible for designing and setting limits to a propellant and rampant pseudo development, rather than draw effective ways and methods for the taxpayer to exercise his right and duty to pay taxes in a fair and humane way, from the materialization of ability to pay. Tax reform is one of the main instrumental way of promoting tax justice for national development. Important thus examine the tax taxation as a way to consolidate one of the fundamental objectives of the Constitution, which is the national development, and in return the key role of the State as holder of all imposing competence in the tax area.
\end{abstract}

Keywords: Tax justice, Tax, Development

\footnotetext{
${ }^{1}$ Doutorando em Ciências Jurídicas pela Universidade Federal da Paraíba, UFPB - PB, ( Brasil).Professor de graduação e coordenador do Núcleo de Prática Jurídica, NPJ da UFPB - PB, (Brasil). E-mail: bbastos.adv@gmail.com

${ }^{2}$ Mestranda em Direito Econômico. Atualmente é coordenadora pedagógica da Escola Superior de Advocacia da Paraíba PB, (Brasil). E-mail: edjane0609@hotmail.com
} 


\section{INTRODUÇÃ̃O}

A Justiça Fiscal tributária, atrelada ao aspecto desenvolvimentista do Estado, tem sido preocupação de estudiosos de áreas multidisciplinares, devido não estar adstrito apenas a seara jurídica. Percebe-se que há clara confusão entre o entendimento de desenvolvimento com o apanágio econômico do crescimento, estando esse atrelado apenas à vertente do crescimento do Produto Nacional Bruto (PNB), deixando fora de órbita outras questões deveras relevantes, tais como aspectos sociais, ecológicos, humanos, etc.

Ocorre que, as liberdades usufruídas pelos indivíduos como aumento da renda per capita, apenas não compreende o verdadeiro sentido do objetivo fundamental presente na Constituição Federal, de 1988, explanado no seu artigo terceiro, inciso segundo. Deve haver entre os entes Federados uma propulsão aos segmentos políticos, social e econômico, instrumentalizado assim numa garantia por parte do Estado de efetivação de todos os seus objetivos fundamentais, estritamente relacionados com a relação jurídica tributária.

É possível afirmar que a claramente que a carga tributária suportada pelos contribuintes deve ser proporcional a riqueza dos mesmos, devendo assim, ocorrer um prestígio à tributação direta, para que seja possível uma superação gradativa da denominada injustiça fiscal. Como reflexo dessa injustiça, ocorre um fortalecimento das desigualdades sóciopolíticas, tanto em âmbito interno como externo aos entes federados, reflexo esse que deve ser rechaçado, na busca incessante pelo estabelecimento da justiça fiscal e estabelecimento do bem comum social, por parte do Estado.

Portanto, o fomento de justiça fiscal no ordenamento tributário brasileiro passa pela desconcentração da arrecadação dos tributos indiretos e o efetivo exercício da progressividade, concretizando o princípio da capacidade contributiva, se revelando um dos caminhos mais largos e propensos à efetivação desse ideal.

Outro fator importante é com relação à segurança jurídica, que tem sido afetada neste campo devido, as inúmeras normas existentes e as que a cada dia são criadas para justificar o poder de interferência que o ente tributante possui, fazendo com que haja uma justificativa "ilegal”, mas legítima, do Estado ter como único e desvirtuado objetivo, o de arrecadação, em vez, de diretrizes embasadas no desenvolvimento político, econômico e social, impresso nos direitos geracionais constitucionais.

A efetivação de uma reforma tributária brasileira parece ser instrumento imperioso para a concretização do projeto de desenvolvimento nacional, processo multidisciplinar e que 
deve ser mobilizado pelo Estado e as mais variadas instituições públicas ou privadas para que o país atinja realmente a seus objetivos constitucionais, e satisfação das necessidades sociais. Os indivíduos têm contribuído com parcelas de tributos exorbitantes com vistas ao remanejamento por meio dos serviços básicos essenciais que devem ser efetuados pelo Estado como contrapartida para sociedade, o que se dá de forma precária na realidade brasileira.

O presente artigo visa de forma geral discutir os meios de implementação da justiça fiscal tributária como forma de garantir e promover o desenvolvimento nacional, uma vez que a implementação efetiva é o fator de maior dificuldade de concretização do desenvolvimento.

\section{A EVOLUÇÃO CONSTITUCIONAL DO DIREITO TRIBUTÁRIO A PARTIR DA CONSTITUIÇÃO FEDERAL DE 1988}

A Constituição cidadã, outorgada em 05 de outubro, de 1988, totalmente imbuída dos princípios sociais da Constituição de Weimar e da Lei Fundamental de Bonn veio revolucionar com relação às garantias fundamentais, uma vez que o rol de direitos já vinha sendo desenvolvido no decorrer das Constituições anteriores. Assim, o texto vigente trouxe métodos e princípios os quais viabilizassem a efetivação das garantias fundamentais dos indivíduos integrantes da sociedade.

Alguns direitos sociais foram definidos nessa Carta política como: os valores sociais do trabalho e a livre iniciativa; cimentou ainda os objetivos fundamentais para a república como o desenvolvimento nacional, a erradicação da pobreza e da marginalização, a subjugação das desigualdades sociais e regionais, em outro capítulo da mesma Carta trata também sobre os direitos sociais dos indivíduos, os quais englobam de forma ampla o trabalho, o lazer, a educação, a saúde, a previdência social, a segurança, o abrigo a maternidade, a criança e aos desempregados.

As constituições até aqui existentes não possuíam a efetividade material de suas normas, sendo assim, a Carta Constitucional de 88 foi responsável por romper as barreiras das normas apenas em abstrato e do autoritarismo retrógrado dos sistemas políticos vigentes até então, pois, instrumentos foram criados com o fito de efetivarem as normas, garantido assim os direitos fundamentais positivados. Esse conjunto de normas possui supremacia perante as outras normas infraconstitucionais, fator esse que coloca a Constituição no ápice da pirâmide Kelseniana e aplicação prioritária de suas normas cogentes, no ordenamento jurídico.

Sendo assim os princípios como instrumentos viabilizadores de aplicação efetiva da norma abstrata, até então, seguirão uma sequência no ordenamento jurídico brasileiro vigente: 
preeminência da Constituição, o da presunção de constitucionalidade das normas e atos do poder público, o da interpretação conforme a Constituição, o da unidade, o da razoabilidade e o da efetividade. É ratificado aos princípios a normatividade dos mesmos, porém, não há uma superioridade entre si mas, sim o mais adequado à solução em que houve conflito de normas ou colisão entre os princípios, os quais serão direcionados pelo princípio preeminente na atualidade que é o da Dignidade da Pessoa Humana.

O sistema tributário foi reestruturado com princípios que unificaram o sistema com relação a uma figura base de tributo, havendo também o estabelecimento efetivo de limites ao poder de tributar do Estado, fundamentais para a ampliação do sistema de proteção aos contribuinte na relação jurídica tributária.

\subsection{A Constituição Federal de 1988 e as Limitações Constitucionais ao Poder de Tributar}

A Carta constitucional inovou de forma plausível no sentido de que, de maneira efetiva e clara, houve positivação acerca de limitações aos entes estatais no que tange à imposição das exações, em benefício dos cofres públicos, ou seja, a Constituição Federal de 1988 foi um marco no Direito Tributário, pois solidificou as Limitações ao Poder de Tributar do Estado, protegendo os direitos fundamentais dos contribuintes-cidadãos.

Possível conceitura o poder de tributar como "um poder de direito, lastreado no consentimento dos cidadãos, destinatários da invasão patrimonial, tendente à percepção do tributo". (SABBAG, 2010) Assim, o poder de tributar se revela uma parcela da soberania que Estado, que recebe do detentor original do poder em um território politicamente organizado, ou seja, do povo.

Nessa mesma linha de entendimento o poder de tributar "é uma decorrência inevitável da soberania que o Estado exerce sobre as pessoas de seu território, ao qual corresponde, por parte dos indivíduos, um dever de prestação". (NOGUEIRA, 1973, p.140)

Diante dessas explanações podemos ratificar que o poder de tributar é "poderdireito" e não "poder-força", uma vez que, os próprios integrantes da sociedade organizada reconhecem ao Estado o monopólio da violência física legítima de forma bem sucedida, tal como ensina o professor Paulo Bonavides (2006, p.70), com o objetivo que esse proteja e supra de forma efetiva o bem comum social, cumprindo assim a soberania estatal.

O texto positivado pela Constituição Cidadã regulou a relação jurídica entre contribuinte e Estado, ou ainda, governante e governado no momento em que inseriu em sua 
substância textual as normas jurídicas de crivo tributário, onde nessas reparte para cada ente estatal suas competências tributárias específicas; e os princípios explanados do decorrer do texto constitucional que angariam, na maioria das vezes a repressão aos abusos do próprio Estado contra os direitos intrínsecos aos indivíduos. As garantias fundamentais deveriam assim, serem garantidas pelo próprio Estado devido esse ter sido legitimado pelo povo para tal função protetora.

Os princípios jurídicos possuem uma função dúplice no nosso ordenamento jurídico, pois ao mesmo tempo em que servem de fundamentos da norma revestem-se também de caráter normativo, mas, modelável a cada caso concreto devido buscar na balança sóciojurídica o peso do mais justo, ou seja, o equilíbrio chamado de justiça.

O entendimento de Roque Antônio Carraza (1995, p.29) acerca dos princípios jurídicos é que:

Princípio é um enunciado lógico, implícito ou explícito, que, por sua grande generalidade, ocupa posição de preeminência nos vastos quadrantes do Direito e, por isso mesmo, vincula, de modo inexorável, o entendimento e a aplicação das normas jurídicas que com ele se conectam.

Percebe-se assim a importância dos princípios para todo o sistema jurídico pátrio, base fundamental das normas regulamentadoras dos limites que contornam as garantias de todo um Estado Democrático de Direito.

$\mathrm{Na}$ ótica da busca pela aplicação da justiça tributária social, não é possível deixar de citar o Princípio da Igualdade, o qual dentro do complexo constitucional vigente possui valor supremo, pois dentro da interpretação de tal sistema em favor da sociedade sempre deve ter aquele princípio como supedâneo, pois, o mesmo materializa todos os tipos de liberdades dos indivíduos componentes de um Estado social, integrado por tais instrumentos de efetivação das normas jurídicas. Paulo Bonavides (2008, p.376), sobre tal princípio, afirma que "deixou de ser a igualdade jurídica do liberalismo para se converter na igualdade material de nova forma de Estado".

\section{CAPACIDADE CONTRIBUTIVA E SUAS DIMENSÕES}

Com base nos fatos históricos, o surgimento do princípio da capacidade contributiva deu-se na Constituição Imperial do Brasil de 1824, onde explanava em seu artigo 179, inciso $\mathrm{XV}$ que "ninguém será exepto de contribuir para as despesas do Estado na proporção dos seus haveres". 
$\mathrm{Na}$ Constituição posterior esse princípio foi suprimido, onde foi retomado com positivações múltiplas na Carta Social de 1934, por conseguinte, na Positivação Constitucional de 1937 não foi esse princípio tratado, contudo, a Constituição de 1946 trouxe mudança reproduzindo esse instrumento igualitário para os contribuintes no art. 202, a prolação que muito parece com a definição da Constituição de 1988: “os tributos terão caráter pessoal sempre que isso for possível, e serão graduados conforme a capacidade econômica do contribuinte".

Conforme menciona Eduardo Sabbag (2010, p.153), com o fim do Período Negro do Ditatorialismo o princípio da capacidade contributiva ressuscitou com a Reforma Tributária que houve com a Emenda Constitucional 18, de 1965, anteriormente, comentada. Já na Carta Cidadã vigente o art. 145, § $1^{\circ}$ explana definição similar ao artigo 202 da Constituição de

1946, alterou a expressão tributos por impostos.

É possível afirmar que o princípio da capacidade contributiva é corolário ou preeminência do princípio da igualdade, ou seja, a capacidade contributiva é o caminho que aquele princípio usa para atingir o seu fim colimado que é o estabelecimento do ideal de justiça fiscal.

O texto constitucional assim trata a matéria (BRASIL, 1988):

Art. 145. A união, os Estados, o Distrito Federal e os Municípios poderão instituir os seguintes tributos: (...)

$\S 1^{\circ}$. Sempre que possível, os impostos terão caráter pessoal e serão graduados segundo a capacidade econômica do contribuinte, facultado à administração tributária, especialmente para conferir efetividade a esses objetivos, identificar, respeitados os direitos individuais e nos termos da lei, o patrimônio, os rendimentos e as atividades econômicas do contribuinte.

Logo, os contribuintes devem cumprir com as exações impostas pelo Estado de acordo com o bônus do balanceamento proporcional de suas rendas e posses, e não pelas qualidades personalíssimas daqueles, como cor dos olhos, dos cabelos, ou qualquer outro atributo pessoal. Salientamos ainda que, o dever-habilidade de pagar imposto ("ability to pay”) não está restrito apenas aos cidadãos brasileiros, mas, engloba além desses os estrangeiros e apátridas, vetor esse que justifica a não utilização do termo "cidadão", na inteligência do artigo explanado acima.

Percebe-se também que, o princípio da personalização dos impostos é colocado no artigo citado, uma vez que o legislador positivou a expressão impostos em vez de tributos, como falado anteriormente, contudo, o parágrafo primeiro do art. 145 deve ser interpretado de forma 
extensiva, pois, os impostos, aqui, englobarão outros tributos, como exemplo às contribuições para a seguridade social e as taxas, onde o Supremo Tribunal de Federal - STF, por meio da Súmula 665 consolidou esse entendimento extensivo.

Referindo-se ao dito "sempre que possível" entende-se com base na boa doutrina que dependerá de cada meio de concretização da capacidade contributiva para ser usada a melhor técnica de estabelecimento da igualdade tributária, onde o legislador tem o dever de aplicar a imposição de exação tributária conforme a pessoalidade do sujeito passivo, só em casos específicos de determinados meios instrumentais é que aquele poderá usar o critério de graduação com base na capacidade econômica do sujeito passivo da relação tributária. A capacidade contributiva tem como instrumentos viabilizadores de materialidade isonômica os subprincípios constitucionais que são: progressividade, proporcionalidade e seletividade.

\section{A REFORMA TRIBUTÁRIA COMO FORMA DE CONCRETIZAÇÃO DA JUSTIÇA FISCAL TRIBUTÁRIA E EFETIVAÇÃO DO PRINCÍPIO DA DIGNIDADE DA PESSOA HUMANA}

A carga Tributária que é arrecadada no Brasil tem como alvo precípuo a satisfação econômica das necessidades básicas como saúde, educação, produção de emprego, ou seja, fornecer serviços públicos essenciais de qualidade para o cidadão-contribuinte. Sendo assim, a cobrança dos tributos tem como fundamento as ações do Estado como prestador de serviços, os quais viabilizam os cidadãos terem uma vida saudável, atendimento imediato a tratamentos de saúde, segurança, condições humanas de moradia, entre outras garantias fundamentais mínimas para um efetivo bem estar social e, consequente início ao processo de efetivação do princípio da dignidade da pessoa humana, com base em uma universalização desses direitos.

\subsection{O Modelo Tributário Atual e a Ineficácia na Concretização dos Objetivos Constitucionais}

O Estado tem como base Constitucional os objetivos fundamentais expostos no art. $3^{\circ}$ da Constituição Federal (BRASIL, 1988), dentre eles o inciso II, que menciona a garantia ao desenvolvimento nacional. Caso tais objetivos fossem concretizados materialmente, aí sim seria possível falar em efetivação do Princípio da Dignidade da Pessoa Humana. Porém, a realidade que o Brasil está inserido é o da contra mão da materialização dos princípios 
constitucionais propostos pela Constituição cidadã, uma vez que ainda é grande a regressividade no sistema tributário nacional, onde os pobres arcam com exações tributárias mais onerosas do que os ricos, o que gera uma sociedade injusta, preconceituosa e exclusiva. Além disso, existem diferenças exorbitantes nas parcelas de repasse financeiro dos tributos para os diferentes entes estatais causando maior desigualdade regional e atraso no desenvolvimento nacional, logo, em suma demonstram-se situações de discriminação.

A parcela arrecadada aos cofres públicos como parcela pecuniária impositiva para custear os gastos do Estado podem ser divididos em tributos diretos e tributos indiretos. Os tributos diretos estão ligados à incidência sobre a renda e o patrimônio; já os tributos indiretos incidem sobre o consumo de bens e serviços. Os tributos diretos devido serem suportados diretamente pelos contribuintes de fato, ou seja, aquele que paga de imediato o tributo, e estão mais propício à técnica da progressividade, o que fará transparecer "maior equidade e justiça fiscal, pois os maiores possuidores de patrimônio e detentores de renda contribuirão mais" (MARIA; LUCHIEZI JUNIOR, 2010, p. 125), a exemplo do Imposto de Renda (IR) e Impostos sobre Propriedade Predial e Territorial Urbana (IPTU).

Os impostos indiretos são cobrados ao consumidor final, que paga uma tributação excessiva, com efeito, cascata, o que faz nascer uma injustiça fiscal, pois o ônus que as famílias pagam desse imposto sobrepõe-se ao nível de sua renda. Consequentemente, esse fato alimenta a regressividade do nosso conjunto de arrecadação tributária.

A regressividade tem crescido no país, no decorrer de anos, pois essa faceta da tributação indireta, a qual incide sobre o consumo de bens e serviços, tem forte reflexo nos contribuintes de baixa renda, os quais estão pagando mais impostos do que os indivíduos que possuem renda mais consideráveis, sendo assim, esses ficam em posição de vantagem, pois, ganham mais e pagam menos quando comparado com o indivíduo que ganha um salário mínimo e paga a mesma quantia e tributos que aquele pagou, devido terem adquirido os mesmos produtos. Assim, nessa situação não houve um tratamento desigual na medida da desigualdade para garantir a igualdade material da parte menos abastada.

$\mathrm{Na}$ medida em que a renda familiar aumenta os tributos diretos crescem, no entanto, não de forma proporcional para suportar a incidência direta no orçamento familiar, ou seja, há uma retração nessa proporção que deveria ser direta, o que explica o índice de regressividade no nosso sistema tributário.

Destarte, para ser alcançada justiça fiscal tributária, a tributação deve ser prioritariamente direta e progressiva. Nessa medida, ela alcança a justiça social por meio de 
tratamento tributário equânime, proporcionando uma justiça distributiva com uma maior tributação sobre a renda do que sobre o consumo.

\subsection{A REFORMA TRIBUTÁRIA COMO CAMINHO NECESSÁRIO À JUSTIÇA FISCAL}

No presente artigo, já foi anteriormente mencionado que o cidadão tem a obrigação de pagar imposto ("ability to pay") e evidencia-se nessa esteira que da mesma forma o Estado deve proporcionar um ambiente de proteção para esses contribuintes, onde antes de serem indivíduos sobre os quais recai uma prestação pecuniária imposta por aquele, são seres humanos que possuem direitos humanos fundamentais intrínsecos a sua essência, pelo fato de serem pessoas de direitos e deveres.

É fácil perceber que da mesma forma que o cidadão deve contribuir para viabilizar financeiramente as prestações sociais do Estado, o mesmo deve efetuar sua contrapartida junto à sociedade com o fito de cumprir sua obrigação precípua, ou seja, fornecer segurança e bem estar social aos indivíduos integrantes de seu espaço físico e político, sem intervir diretamente nas relações privadas desses cidadãos, mas sim viabilizar uma vida digna aos mesmos e suas famílias, já que o próprio Estado tem sido contraditório em seus objetivos, pois, em vez de garanti-los tem criado medidas inversas, com base nas afirmações redigidas até então.

O dever do cidadão de pagar imposto reflete diretamente no atributo da cidadania tributária daquele, o qual deve ter consciência do ciclo de realização tributária que influencia diretamente em sua vida, independente de classe social, pois, tanto pobre como rico tem exações tributárias impostas pelo Estado.

Logo, o Estado tem que criar medidas efetivas para que seja divulgada de forma ampla uma educação direcionada à informação aos cidadãos-contribuintes no sentido de proporcionar aos mesmos o entendimento de como suas contribuições são utilizadas e, a importância dessas para o custeio dos serviços essenciais para estabelecimento de uma sociedade justa e igualitária, principalmente em relação ao acesso aos serviços essenciais, livre de qualquer sujeição à região em que estejam localizados ou de sua capacidade contributiva.

A Declaração Universal dos Direitos à Justiça Fiscal, edificada no Fórum Mundial, em Porto Alegre, no ano de 2002 (MOSCON, 2011), consolida as colocações, acima, vejamos: 
Preâmbulo: Considerando que todo Estado ou coletividade de Estados deve assegurar a igualdade dos direitos dos homens e das mulheres, favorecer o progresso social, instaurar condições de vida dignas e decentes para todos, e assegurar o desenvolvimento sustentável. Considerando que toda produção de riquezas deve ser acompanhada de uma necessária redistribuição equitativa. Considerando que a fiscalidade deve constituir um dos meios indispensáveis à distribuição de riquezas e a possibilitar o financiamento dos serviços públicos: Nós proclamamos no Forum social de Porto Alegre a presente Declaração universal de direitos à justiça fiscal como elemento da justiça social.

Art. $1^{\circ}$ Toda lei fiscal deve ser objeto de um verdadeiro debate democrático e levar em conta as noções de interesse geral de redistribuição, de justiça e de progressividade das imposições;

Art. $2^{\circ}$ Toda pessoa física ou jurídica deve contribuir aos impostos em função do conjunto de seus rendimentos e/ou benefícios, bem como sobre o capital acumulado; Art. $3^{\text {o }}$ Todo sistema fiscal deve privilegiar os impostos diretos por serem mais justos que os impostos indiretos;

Art. $4^{\circ}$ Toda lei fiscal deve procurar o justo equilíbrio entre a imposição sobre os rendimentos do trabalho e do capital;

Art. $5^{\circ}$ Todas as transações financeiras internacionais devem ser objeto de uma taxação (imposição tributária);

Art. $6^{\circ}$ Todos os produtos e os serviços indispensáveis por assegurar as condições de vida dignas e decentes aos cidadãos não devem fazer parte de imposição tributária; Art. $7^{\circ}$ A aplicação da lei fiscal deve exigir o pagamento dos impostos dentro do país em que as riquezas são produzidas e dar publicidade das imposições;

Art. $8^{\circ}$ Toda fraude fiscal deve ser considerada como um atentado à ordem publica e ao bem estar geral. A fraude fiscal é um roubo. Quem rouba a coletividade, rouba os pobres;

Art. $9^{\circ}$ Todo país que praticar o dumping fiscal, constituir um paraíso fiscal, ou favorecer a sua existência, deve ser considerado como contrário aos interesses gerais e deve ser condenado a abolir essas praticas prejudiciais;

Art. $10^{\circ}$ Para permitir assegurar a independência, a neutralidade e o tratamento igualitário dos cidadãos em relação a aplicação da lei, todos os cargos fiscais devem compor os serviços públicos por agentes regidos por um estatuto público, beneficiário da garantia do emprego.

Em suma, efetivar-se-á justiça fiscal tributária e social no Brasil quando os órgãos estatais conseguirem arraigar a progressividade, suprimindo assim a regressividade avassaladora e, a extinção da corrupção em um sistema tributário vulnerável e ultrapassado; cedendo lugar a um sistema de exações proporcionais a capacidade contributiva dos contribuintes e rezando de forma integral os direitos sociais dos mesmos, os quais fundamentarão uma vida social digna e com liberdade de transação para tais indivíduos angariarem efetivamente sua subsistência vital.

Complementando todas essas medida para trazer à existência material a justiça fiscal tributária e estabelecimentos das diretrizes constitucionais, gerando assim, o bem estar social vem à necessidade de uma modificação positiva no complexo tributário brasileiro, vigente.

Sabe-se assim que é necessária a concretização de uma Reforma Tributária em nosso país, com vista à melhoria social e promulgação de uma justiça fiscal tributária, a qual 
viabilize de forma interativa o valor final para o qual convergem progressivamente os resultados das sucessivas interações das garantias constitucionais.

Assim, com base no que foi supracitado, à distribuição dos recursos provenientes da arrecadação tributária deve viabilizar que todo cidadão, inserido em qualquer localização do espaço físico do Estado deve ter passagem qualificada ao uso dos serviços públicos, os quais devem ser suficientes para atender a procura. E ainda, não podemos deixar de explanar que uma Reforma Tributária não pode ocorrer se não contiver um amplo processo de cidadania tributária, ou seja, discussão efetiva acerca dos assuntos diretamente ligados as exações tributárias e seus efeitos, já que tais assuntos estão inseridos no gerenciamento fiscal administrativo.

Destarte, necessário estabelecer uma Justiça Fiscal Tributária, no Brasil, onde os objetivos e direitos fundamentais constitucionais serão vividos de forma plena e eficaz, já que sairão da mera formalidade positivista para realidade jusnaturalista. Tais propostas fornecerão mais renda para as classes média e baixa, as quais refletirão no aumento da liberdade de transação dos indivíduos dessas classes, o que faz nascer um ciclo "virtuoso do crescimento sustentado, que, em última análise, terá significativo impacto positivo nos lucros dos setores produtivos da sociedade" (MARIA; LUCHIEZI JUNIOR, 2010, p. 188).

\section{TRIBUTAÇÃO E A PROMOÇÃO DO DESENVOLVIMENTO}

Como já mencionado, o texto constitucional estabelece expressamente objetivos fundamentais os quais devem ser atendidos por todo o ordenamento infraconstitucional. Com supedâneo nessa meta constitucional de garantir o desenvolvimento constitucional vários doutrinadores buscam definir o que seria desenvolvimento, devido sua importância para o desenrolar de todas as garantias aos indivíduos integrantes da nação brasileira.

\subsection{Delimitação Conceitual de Desenvolvimento: Desenvolvimento Versus $x$ Crescimento Econômico}

Para Amartya Sen (2000, p. 51), o processo de desenvolvimento traduz-se em um processo feroz e amigável, onde o primeiro iter demonstra-se por meio de algumas privações as quais devem ser efetuadas com vistas a atingir o desenvolvimento, uma vez que quando esse 
for realmente atingido devolverá aos cidadãos a prática das medidas evitadas, contudo, de forma correta quando "o processo de desenvolvimento houver produzido frutos suficientes: o necessário aqui agora é dureza e disciplina” (SEN, 2000, p.51).

Ao contrário dessa primeira visão, emerge a óptica de análise do desenvolvimento como um processo amigável, discorrido por Adam Smith, onde afirma que por meio das "redes de segurança social, de liberdades políticas ou de desenvolvimento social - ou por algumas combinações dessas atividades sustentadoras" o desenvolvimento será materializado no país que exercer tais mobilizações.

Essa última visão é compactuada por Sen em sua definição de desenvolvimento, quando considera que para se chegar ao fim efetivo do processo de desenvolvimento é necessário ser concretizado o papel constitutivo, ou seja, as liberdades serem garantidas como fim primordial, devido tais liberdades serem papel instrumental na geração do principal meio do desenvolvimento, e consequente estandarte da garantia aos direitos universais dos cidadãos.

O desenvolvimento é um processo complexo e continuado em uma nação, e não uma linha lógica que leva ao desembocar do mesmo, pois, essa busca pelo desenvolvimento também pode ocorrer retração se as práticas tendentes aquele processo não forem bem aplicadas ou se as práticas negativas forem disseminadas.

Mahbu bul Hag (in BARRAL, 2005, p.17) defende o conceito de desenvolvimento de forma radical como sendo uma visão integrada e inseparável dos desenvolvimentos humano, jurídico e econômico; no entanto, esse entendimento extremista não é muito bem aceito por Sen, onde esse em seu discurso no Prêmio Nobel de Economia afirma que uma visão totalmente unificada pode ser sem compromisso, pois, o desenvolvimento pode ser visto por partes que somadas formam o processo de desenvolvimento, ou seja, o desenvolvimento econômico de determinada região pode ocorrer de forma positiva enquanto que, o desenvolvimento político pode está na busca pelo mesmo desempenho que houve na parte econômica, e assim por diante, sem pressupor que um deve vir com o outro.

Contudo, para haver um desenvolvimento tout court (BARRAL, 2005, p.17), ou seja, um processo completo de desenvolvimento, todas as áreas constitutivas do mesmo devem ter sido consideradas e/ou analisadas pelas instituições que promulgam o mesmo.

A maior barreira que a conceituação do desenvolvimento deve transpor é a restrição às teorias que vinculam o desenvolvimento ao crescimento econômico ou ao poder estatal; e ainda sair da teoria para execução prática do desenvolvimento, conforme ensina o professor Welber Barral (2005, p.19), pois, o processo de desenvolvimento é muito mais amplo e 
complexo que o crescimento econômico, o qual é apenas uma das facetas daquele. Para a materialização do desenvolvimento deve haver cumulação de fatores históricos, geográficos e sociais, os quais serão viabilizados por matriz institucional eficaz (BARRAL, 2005, p.33).

Com base no Diálogo para o Desenvolvimento desenvolvido pelo Conselho de Desenvolvimento Econômico e Social - CDES, “o desenvolvimento é um fenômeno multifacetado ou multidimensional, não consiste somente em crescimento econômico, e industrialização ou expansão industrial, é apenas parte" (CARDOZO JUNIOR, 2010, p. 36).

Destarte, aqui, é perceptível que o processo de desenvolvimento vem arraigado aos valores e costumes consistentes em uma sociedade, onde refletem várias peculiaridades de diferentes caracteres como, físico, vital, cultural, econômica, ambiental, social, institucional e política.

Nessa toada, vê-se, pois, que o prisma físico como a utilização garantida e eficaz dos recursos naturais do planeta, desde que de forma da invenção sustentável. No que tange ao sentido vital é a satisfação aos indivíduos de saúde, educação, alimentação, lazer, bem estar social, entre outros atributos para um indivíduo considerar-se viver bem.

O sentido cultural relaciona-se com a construção do capital social, ou seja, os seres componentes da sociedade terem imbuído sentimento coletivista de resguardarem os bens e valores que contribuem para tal coletividade está unida harmonicamente. Ademais, o desenvolvimento na ótica econômica é o aumento considerável no mercado interno e externo o qual deve viabilizar participação inclusiva dos mais diferentes setores e regiões, devendo também ser conscientizado que o consumo não pode ser promulgado como finalidade lucrativa, mas sim necessidade.

Cumpre ressalta ainda a faceta ambiental que é direcionada aos anseios do meio social por prestação de serviços essenciais, como acesso a água tratada, a um saneamento básico, entre outros serviços locais, contudo em macro nível podemos afirmar o desflorestamento, a poluição em suas várias espécies, assim como, a ameaça extinção das espécies animais.

Na Época Moderna vivenciada, alguns pontos foram sugeridos como contribuições importantes para implementação do processo de desenvolvimento, pois, o que mais é criticado na teoria de Sen - Desenvolvimento como Liberdade, é justamente a forma como esse desenvolvimento será implementado em dado Estado de forma eficaz; logo, estes fatores foram suscitados os quais discorreremos nesta ocasião. 
Indivíduos com nível elevado de informação e educação, os quais são importantes na construção de uma sociedade mais participativa e consciente do que ocorre aos seus redores, desembocando assim em substrato ao capital social e estabelecimento da justiça fiscal tributária, devido à busca maior de repressão a corrupção, diminuição na perda de arrecadação e baixa dos custos com fiscalização.

Outro fator relevante é a disseminação de novas técnicas científicas e de produção que instrumentalizam medidas ratificadoras de desenvolvimento em vários setores, ou seja, tecnologia ascendente utilizada para promulgar a técnica desenvolvimentista. Ressaltamos ainda, a estrutura da produção exacerbada que saiu da simples produção com fito de suprir uma demanda baseada na escassez para uma produção que sustenta o ciclo do capitalismo, uma vez que esse tipo de produção passou a ser um fim em si (BARRAL, 2005, p.42).

As instituições que promovam os fatores até aqui explanados são consideradas legítimas para promoção do desenvolvimento nacional, pois, refletem confiança e credibilidade com vistas a garantir também a materialização da justiça fiscal quando buscam veementemente, formas eficazes de reprimir todos os tipos de corrupção e atos ilícitos que sirvam de escada para as ilegalidades tributárias e socioeconômicas.

\subsection{Justiça Fiscal Tributária como Fator Primordial no Processo de Desenvolvimento}

Destarte, é perceptível a necessidade de uma Reforma Tributária e estabelecimento da Justiça Fiscal Tributária, pois, não é possível falar em desenvolvimento caso não haja uma mudança por parte do Estado e estrutura regulatória, na soma dos elementos que caracterizam a estrutura socioeconômica, pois caso contrário, não existe efetividade na distribuição e descentralização de renda, e, consequente respeito às diferentes capacidades contributivas existentes na sociedade brasileiras (BERCOVICI, 2005, p. 53).

Conforme entendimento de Eros Roberto Grau (2007, p. 264), o crescimento econômico, como parcela integrante do desenvolvimento, é necessário, contudo, apenas a acumulação de renda não é mais suficiente para cumprir com políticas públicas e objetivos estatais viabilizadores da Justiça Fiscal, sendo que, além de acumular riqueza o Estado deve acumular saber e tecnologia.

O Brasil necessita de uma reforma em sua estrutura estatal, que traga uma redefinição em seu planejamento com substrato nos objetivos nacionais, em vez de interesses privados dominantes e dirigismo desvirtuado famigerante em alargar o calabouço das 
desigualdades sociais, as quais têm sido fomentadas pela modernização desenfreada. Ressaltamos ainda que, o crescimento sem desenvolvimento é o processo que ocorre atrelado à modernização, contudo, sem qualquer mudança estrutural, trazendo como consequência um modelo de Estado que não propaga de forma efetiva o bem-estar social, mas, sim, um Estado excludente que prioriza a cobrança de tributos indiretos (BERCOVICI, 2005, p. 53).

Como bem observou Eros Grau, "o processo de desenvolvimento deve levar a um salto, de uma estrutura social para outra, acompanhado da elevação do nível econômico e do nível cultural-intelectual comunitário" (2007, p. 216), por conseguinte, insta salientar que é necessário a concretude da Justiça Fiscal para que esse salto social seja dado.

A promoção do desenvolvimento não se limita as políticas públicas realizadas por determinado ente estatal, pois, aquelas podem ser vistas assim apenas se tratarmos as políticas públicas como faceta precípua do desenvolvimento nacional. Portanto, para o projeto de desenvolvimento nacional ser estabelecido de forma efetiva deve haver uma junção de várias forças, medidas e disciplinas com fito de alterar a estrutura regulatória do Estado, o qual agirá com vista principal ao cumprimento dos seus objetivos, que serão aperfeiçoados pela Justiça Fiscal Tributária depois de uma eficaz Reforma Tributária, viabilizando de forma instrumental a linha revolucionária de superação ao subdesenvolvimento em todos os setores, seja, econômico, social, cultural, físico, científico, ambiental, político, entre outros que somados resultam no "tout court" - desenvolvimento humano completo.

Nesta senda, será viabilizada uma integração regional que dará materialidade a planejamentos sérios e que respeitem as verdadeiras necessidades de toda sociedade e não de interesses de classes específicas, desembocando ainda em reprimir variadas guerras fiscais, "devido à política predatória de atração de indústrias para as Regiões menos desenvolvidas" (BERCOVICI, 2005, p. 53)

Destarte, vê-se, pois, que a promoção do desenvolvimento pelo Estado como forma de construir uma sociedade livre, justa e solidária, fomentando uma tributação justa e solidária, com base na equidade traz a existência em nosso país a concretização de uma Justiça Fiscal tributária como forma de garantir o desenvolvimento necessário para subsistência digna dos contribuintes-cidadãos, integrantes da nação brasileira. 


\section{CONSIDERAÇÕES FINAIS}

Portanto, no decorrer do presente artigo foi possível detectar que a constitucionalização dos direitos foi um passo considerável em nosso sistema jurídico tributário. Com a evolução da organização jurídica foi possível sair de um sistema jurídico absolutista para uma Constituição Cidadã, a qual rompeu com o autoritarismo retrógrado e formalidade positivista na busca de garantir os direitos materiais.

A alta carga tributária é um grande fator negativo contrário à justiça fiscal tributária e promoção do desenvolvimento nacional, pois, o Estado arrecada uma bruta parcela pecuniária dos cidadãos-contribuintes com o objetivo se efetuar os serviços públicos essenciais da melhor forma possível para possibilitar àqueles terem uma vida digna, contudo, isso não tem ocorrido nessa sequência, onde o Estado não tem sido comprometido em realizar materialmente essa contrapartida com a sociedade; e sim tem angariado uma alta arrecadação abusiva; tem criado cada dia mais mecanismos de majoração dessa parcela pecuniária altíssima, sobrepondo, muitas vezes a tributação arrecadada em países desenvolvidos.

A insegurança jurídica fomentada pela complexidade e burocratização nas leis que integram a legislação tributária tem contribuído para as desigualdades sociais e regionais, o que tem ratificado a explanação de que a Otimalidade de Pareto não tem sido cumprida de forma eficaz, uma vez que, o próprio Estado, como responsável, não tem viabilizado tal cumprimento quiçá os seus integrantes, os quais cederam à parcela maior de suas autonomias para que aquele regulasse as situações em proteção às necessidades dos mesmos.

A regressividade tem aumentado drasticamente, já que a tributação tem enfatizado à arrecadação dos tributos indiretos, ou seja, tributos que incidem sobre bens e serviços, os quais não refletem transparência das classes que tributam tratando assim, todas de forma igual, o que faz com que essa igualdade não seja promotora de desenvolvimento, mas sim, de retração a toda e qualquer isonomia, devido os indivíduos mais vulneráveis e que possuem menor renda devam ser tratados desigualmente, na medida de suas desigualdades com vistas ao estabelecimento da igualdade material e geração de integração entre as diferentes classes podendo assim, materializar o tratamento igual sem descriminalização.

Os tributos diretos devem ser veementemente prestigiados visto que, são propulsores a progressividade e justiça fiscal tributária como forma de desenvolvimento; e, ainda nivelar o nível de renda das famílias às contribuições conforme sua capacidade contributiva, pois, não tem como as famílias mais carentes continuarem arcando com quase metade dos gastos que o 
Estado tem com suas despesas, enquanto que as classes mais altas não pagam nem $30 \%$ com as mesmas. Necessário assim, um reajuste dos índices que regulam a tabela do Imposto de Renda.

A Reforma Tributária é inerente à Justiça Fiscal, pois, não tem como viver essa realidade distante da efetuação daquela que soma todas as mudanças materiais que, com certeza não é a solução de todos os problemas fiscais e sociais, porém, indubitavelmente desbravará caminhos da materialidade da Justiça Fiscal Tributária, desestabilizando assim, o ciclo das desigualdades em todos os entes da federação, e fornecendo redistribuição de renda, liberdade de transação, entre outras medidas já citadas, as quais convergem progressivamente para interações das garantias constitucionais.

Destarte, o estabelecimento da justiça fiscal tributária como forma de desenvolvimento nacional se faz necessário no Brasil, onde necessário o estabelecimento de um planejamento que inclua todos os tipos de desenvolvimento, seja social, econômico, político, ambiental, ou a soma de todos, desde que seja na direção de garantir de forma concreta aos indivíduos integrantes da sociedade os seus direitos intrínsecos a sua essência como cidadãos-contribuintes, e que as exações não sejam formas de retirar daqueles a dignidade de sobrevivência, mas, sim sua finalidade precípua, ajudar ao Estado no sustento das suas obrigações para com os indivíduos componentes de seu elemento físico, buscando instrumentalizar as liberdades fundamentais dos indivíduos. 


\section{REFERÊNCIAS}

BARRAL, Welber (org). Direito e desenvolvimento: análise da ordem jurídica brasileira sob a ótica do desenvolvimento, São Paulo: Singular, 2005.

BERCOVICI, Gilberto. Constituição Econômica e Desenvolvimento. São Paulo: Malheiros, 2005.

BONAVIDES, Paulo. Ciência Política. 13. ed., São Paulo: Malheiros, 2006.

. Curso de Direito Constitucional, 23. ed. São Paulo: Malheiros, 2008.

BRASIL. Constituição (1988). Disponível em: http://www.planalto.gov.br/ccivil_03 /Constituicao/Constituicao.htm, Acesso em: 08 ago. 2011.

BRASIL. Supremo Tribunal Federal. Súmula ${ }^{\circ}$ 665. In: Dispõe que é constitucional a taxa de fiscalização dos mercados de títulos e valores mobiliários instituída pela lei 7940/1989. Disponível em: http://www.stf.jus.br/portal/cms/verTexto.asp?servico=jurisprudenciaSumula. Acesso em: 28 ago. 2011.

CARRAZA, Roque Antônio. Curso de Direito Constitucional Tributário, 7. ed. São Paulo: Malheiros, 1995, p. 29.

EMPRESA BRASILIEIRA DE COMUNICAÇÃO, Pobres são mais atingidos pelos impostos indiretos. Agência Brasil. 01 jul 2009 Disponível em: http://direitovivo.jusbrasil.com.br/noticias/1485696/ pobres-sao-mais-atingidos-pelos-impostos-indiretos, acesso em: 07 de out. 2011.

GRAU, Eros Roberto. A ordem econômica na Constituição de 1988. 12. ed. São Paulo: Malheiros,2007.

JUNIOR, José Celso Cardoso; SANTOS, José Carlos dos; ALENCAR, Joana (org.). Diálogos para o Desenvolvimento: a experiência do Conselho de Desenvolvimento Econômico e Social sob o governo de Lula. Brasília: IPEA: CDES, 2010, v. 2.

MARIA, Elizabeth de Jesus; LUCHIEZI JUNIOR, Álvaro. (Org.). Tributação no Brasil: em busca da justiça fiscal. Brasília, [s.n.], 2010.

MOSCON, Cledi de Fátima Manica. Tributação e cidadania: Justiça Fiscal - Da Utopia à efetivação. Coordenadas sobre o Direito de igualdade em matéria tributária e princípios constitucionais como instrumentos a dar efetividade à Justiça fiscal, (s.d). Disponível em: http://www.anfip.org.br/arqs-pdfs/mono_tributacao_cidadania_cledi_02062010.pdf. Acesso em: 19 out. 2011.

NOGUEIRA, Ruy Barbosa. Direito tributário: estudo de casos e problemas. São Paulo: Bushatsky, 1973.

SABBAG, Eduardo. Manual de direito tributário, $2^{\mathrm{a}}$ ed. São Paulo: Saraiva, 2010. 
SEN, Amartya Kumar. Desenvolvimento como liberdade, tradução Laura Teixeira Motta; revisão técnica Ricardo Doniselli Mendes, São Paulo: Companhia das Letras, 2000. 